in the Norfolk Breckland to qualify for inclusion. In Ireland there are ten deer forests, mainly in Counties Donegal, Kerry and Wicklow.

One can have no hesitation in affirming that this very thorough piece of work will hold its own as the standard work on British deer forests until the end of the century, and probably well into the next one as well. But I commend to the Deer Group of the Mammal Society of the British Isles the task of making good use of the vast store of natural history information it contains.

R. S. R. FitTer

\section{GEOMORPHOLOGY OF WALES}

The Relief and Drainage of Wales

A Study in Geomorphological Development. By Eric H. Brown. Pp. xii $+186+24$ plates. (Cardiff : University of Wales Press, 1960.) 30s.

$\mathrm{D}$ URING the course of the past hundred years a considerable diversity of opinion has accumulated concerning the nature, origin and age of the erosion surfaces in Wales. Many of these views are mutually exclusive. Thus the Permo-Triassic age suggested by $\mathrm{O}$. T. Jones conflicts with Jukes Browne's Cretaceous, and both with W. M. Davis's 'Tertiary. A. C. Ramsay's submarine hypothesis is in contradiction with W. M. Davis's subaerial argument, and so on. Equally complex is the problem of drainage evolution. T. N. George supports the view of rivers extending their courses across emergent wave-cut platforms of Pliocene age, while A. Strahan has proposed that the new discordant rivers of South Wales have been superimposed from a Cretaceous cover.

The problems of the evolution of drajnage and the extent, origin and age of the erosion surfaces are closely linked; these together form the basis of the denudation chronology for any given area. For the first time for Wales these two lines of inquiry are brought together in Dr. Eric Brown's study of the relief and drainage of the whole principality. The survey is thus in the tradition of the classic accounts of the French Plateau Central, by Henri Baulig, and. Structure, Surface and Drainage in South East England, by Profs. Wooldridge and Linton.

This new book is the product of many years of study and much field work, and gives for the first time a systematic geomorphological account of much of the landseape of Wales. Although some of the conclusions advanced by Dr. Brown are open to discussion, all those interestod will applaud his introductory survey of the relief and structure of Wales and his masterly account of the views put forward during the past hundred years to account for these features.

In the second half of the book Dr. Brown advances his own interpretation of the denudation chronology in considerable detail. Evidence is submitted for the existence of at least three high-level subaerial peneplains of early Tertiary age above $700 \mathrm{ft}$. : and below this height for a series of coastal plateaux, notably at 600-, 400-, 300-and 200-ft. levels, of submarine origin and Pleistocene age. The drainage evolution is worked out in relation to these erosion surfaces. Forty-seven maps and diagrams and twenty-four plates support the text, and the account concludes with a comprehensive bibliography.
The bibliography will be of great value to future research workers in this field, but it is perhaps unfortunate that there is no reference to Dr. Brown's paper on "The Physique of Wales" given to the Royal Geographical Society on October 29, 1956 (Geo. graphical Journal, 123, Part 2, June 1957). This paper is of great interest and value, as the nature and extent of the problems still outstanding after Dr. Brown's analysis and synthesis of the geomorphology of Wales clearly emerge in the discussion which followed. One other addition to the book might have been considered-a short glossary of Welsh landscape terms. So many Welsh place names arise from the topography that additional interest would doubtless be added for the English reader if an indication of the meanings were made available.

$$
\text { W. G. V. BaLchIN }
$$

\section{INTRODUCING METEORITICS}

\section{Principles of Meteoritics}

By E. L. Krinov. Translated from the Russian by Irene Vidziunas. Translation edited by Harrison Brown. (International Series of Monographs on Earth Sciences, Vol. 7.) Pp. $x i+535+7$ plates. (London and New York: Pergamon Press, 1960.) 70s. net.

THEE original edition of Krinov's introductory book on the study of meteorites has been available in Western meteorite laboratories for some years, but it is doubtful whether many investigators have actually read more than the sections of particular interest to their own work. It is essentially an introductory text, and, as such, may be read with profit by the sort of informed lay public at which Sir Lazarus Fletcher's British Museum guide was directed; but there is also included a section on the external appearance of fusion crusts which represents an important original contribution to the subject by the author himself. D. R. Chapman's recent article on tektites (Nature, 188,$353 ; 1960$ ) indicates how profitably such work may be extended by aerodynamicists.

The treatment is naturally from a Russian point of view, and most of the specialist articles quoted are of Russian origin, but a real effort was made in the original edition to acknowledge the importance of work by Prior and Hey, Perry, Urey and others. The translated version also includes a selection of both Russian and American work published since the original edition.

In so far as I am able to check it, the translation appears very faithful. In the original, the text and legend are at one in their misinterpretation of Fig. 121, whereas in the translation the text follows the original, but the legond (Fig. 129 of the translation) has been altered to a factually correct form.

Several additional illustrations have been incorporated in the translated edition, and some of the original illustrations have been replaced by more up-to-date or clearer ones. In a work of this nature the half-tone illustrations are of great importance, and it is very unfortunate that in reproduction some of them have deteriorated. On the other hand most, but not all, of the new illustrations are of good quality. A very serious loss in the translated edition is the totally inadequate version of Fig. 52, but this could easily be corrected.
H. J. Axon 